\title{
INFLUENCE OF AGGRESSIVE ENVIRONMENT ON THE TENSILE PROPERTIES OF TEXTILE REINFORCED CONCRETE
}

\author{
Jan Machovec ${ }^{a, b}$, Pavel Reiterman ${ }^{a, b, *}$ \\ ${ }^{a}$ Faculty of Civil Engineering, Czech Technical University in Prague, Thakurova 7, Prague 6, 166 29, Czech \\ Republic \\ ${ }^{b}$ University Centre for Energy Efficient Buildings, Czech Technical University in Prague, Trinecka 1024, \\ Bustehrad, 273 43, Czech Republic \\ * corresponding author: pavel.reiterman@fsv.cvut.cz
}

\begin{abstract}
This article deals with the long-term durability of a relatively new composite - textile reinforced concrete (TRC). The studied composite material introduces a modern and favourite solution in contemporary architecture and structural engineering. It could also be used in renovation and monument restoration due to its high utility properties. The experimental program was focused on the determination of the resistance of the TRC in an aggressive environment using durability accelerated tests. The high performance concrete (HPC), which we used in our study, exhibited a compressive strength exceeding $100 \mathrm{MPa}$ after 28 days. Specimens were subjected to a $10 \%$ solution of $\mathrm{H}_{2} \mathrm{SO}_{4}$, $10 \%$ solution of $\mathrm{NaOH}$, and freeze-thaw cycling respectively. All these environments can occur in real conditions in the TRC practical utilization. The testing was carried out on "dog-bone" shaped specimens, specially designed for the tensile strength measurement. Studied TRC specimens were reinforced by textiles of three different square weight that were applied in one or two layers, which led to the expected increase of tensile strength The freeze-thaw cycling had the biggest influence on the tensile properties, because it causes micro-cracks formation. The specimens exposed to the chemically aggressive environment deteriorated mostly on the surface, because of the high density of the concrete and generally low penetration of the media used. The resistance of the studied TRC to the aggressive environment increased with the applied reinforcement rate. The performed experimental programme highlighted the necessity of including the durability properties in the design of structural elements.
\end{abstract}

KEYWORDS: textile concrete; tensile strength; accelerated durability test; acid environment; freezingthawing; alkaline solution.

\section{INTRODUCTION}

Textile reinforced concrete (TRC) is a composite material, which is becoming more and more known. Textile concrete may have one or (usually) more layers of textile reinforcement instead of steel [1 3]. However, mostly $2 \mathrm{D}$ textile reinforcement is used. It can also be prestressed and there are two ways to do that - the mechanical way [1] or by a chemical composition of reinforcement (nylon shrinks in alkali environment) [2].

The TRC is a composite material based on the high-density matrix, usually high-performance concrete (HPC). The concrete matrix used in combination with the textile reinforcement must fulfil several technological conditions. Maximum size of its particles must be smaller than the "eye" of the textile reinforcement and it must be fluid enough to enter all parts. The textile reinforcement is easy to use, it is light and flexible. This material is currently very favoured by architects, which can be declared on the basis of the increasing amount of its application. The TRC is used mostly as facade panels, bridges, decorative roofs, etc. It means that it is used in aggressive conditions very often. That is why its long-term durability is a very relevant issue.
Its long-term durability depends on the properties of particular components. A suitable durability of concrete matrix was studied intensively by a number of research teams [4-6]. High resistance to the action of the environment is ensured by the application of supplementary cementitious materials (SCMs), which significantly reduce the matrix permeability. The most frequently applied SCM is silica fume, however, fly-ash or metakaolin could be successfully used [7 9].

The highest quality textiles are made of carbon, but, at the same time, it is the most expensive additive. Another alternative is glass. Glass itself is very sensitive to alkaline environment, which is typical for concrete; therefore, it needs a surface treatment or a special primary material (AR glass - alkali resistant). Organic materials can be used as well, such as plastics, nylon, hemp, jute, etc., however, these materials can react differently in extreme conditions. They have different coefficient of thermal expansion, chemical properties and are generally sensitive to the degradation.

One of the biggest chemical exposition of acidic solutions is in acid rains. Wang et al. [10] discussed the problem of acid rains in China, it affects almost one third of its area. Not only rain, but industrial 


\begin{tabular}{lc}
\hline Component & Weight ratio $[-]$ \\
\hline Cement CEM I 42.5 R & 1 \\
Silica fume & 0.19 \\
Silica sand 0.1/0.6 & 0.48 \\
Silica sand 0.3/0.8 & 0.5 \\
Silica sand 0.6/1.2 & 0.38 \\
Silica powder & 0.48 \\
Superplasticizer & 0.011 \\
Water & 0.35 \\
\hline
\end{tabular}

TABle 1. Composition of used concrete matrix.

and agricultural environments are exposing concrete to acidic conditions, this problem is not just in China, but worldwide. Facts based on a worldwide comprehensive research [11] shows that almost $54 \%$ of all problems with concrete structures are caused by chemical reactions (carbonation, chloride attack, acids, etc.) and it is mostly caused by a wrong choice of concrete mixture for the required purpose.

Nobili [12] studied the influence of the alkaline environment, which is typical for all concrete structures and used reinforcement must deal with it. A tensile strength experiment of a concrete reinforced with glass textile shown that there is an obvious difference in strength loss between the matrix and textile. The cementitious matrix shown faster degradation (24\% compared to the reference sample) than glass textile (11\%). The glass textile reinforcement can be protected from the influence of the alkali environment by two basic ways depending on the glass used. A lower quality glass is covered in styrene-butadiene layer and higher quality glass, so called AR glass (alkali resistant) contains 15-20\% of zirconium [13, 14, which improves the durability of the glass.

Butler et al. [7, 8] also experimented with the durability of the textile concrete. They mention three factors that are crucial for a long term durability of glass-fibre-reinforced concrete, which has the same damage mechanism as the TRC. First is the Corrosion of the fibre material itself due to attack of $\mathrm{OH}-$ ions in the pore solution, second is Static fatigue of the glass fibre under sustained load in the highly alkaline environment and lastly Densification of the matrix adjacent to the filaments and enhancement of the fibre-matrix bond with continued hydration. The alkalinity resistance is improved by a polymer layer, which also has a mechanical purpose (holds the textile together). The focus of their article was to find the perfect composition of matrix for the best durability results. Experiments showed that metakaolin and fly-ash are the best solution, because they create a high density matrix with a suitable resistance to the aggressive environment. However, cementitious matrixes show better results than the blended binding systems in early stages, because of faster hydration, which caused better bond between the matrix and textile reinforcement.

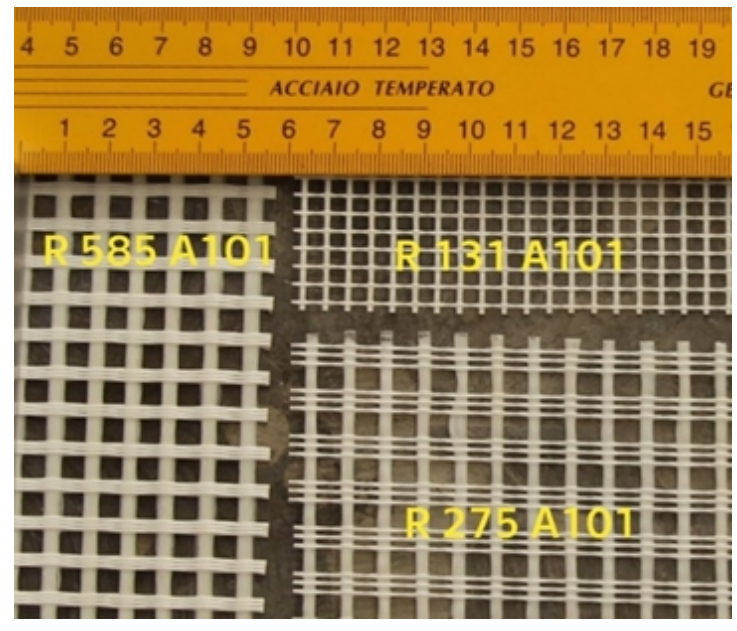

Figure 1. Three types of used textile reinforcement.

The main aim of the present article is to assess the durability of the TRC using a complex system of experimental procedures. The performed set of accelerated tests introduces the most harmful deterioration mechanisms attacking the concrete. Samples of the studied TRC were exposed to freeze-thaw cycling, acid and alkaline environment, respectively, in terms of direct tension tests.

\section{EXPERIMENTAL PROGRAM}

Performed experimental program follows a previous research [15, 16, which was focused on the development of a cement matrix applicable for the TRC production. A new type of Portland cement matrix was formulated and its technological aspects were verified.

\subsection{MATERIALS}

The concrete matrix was based on the HPC, whose composition is shown in Tab. 1. This composite contains a high amount of fine components to obtain the suitable consistency in fresh state. High amount of silica fume significantly reduces the permeability and $\mathrm{pH}$ of pore water. The compressive strength exceeds, after 28 days, $100 \mathrm{MPa}$ when using cubes $100 \times 100 \times 100 \mathrm{~mm}$. Testing was conducted in accordance with BS EN 193 [17.

Name code of textiles is for example "R 585 A101", where R means textile fabric, 585 stands for weight in grams per square meter and A101 is a type of the surface treatment, in this case, alkali resistant. Textiles have different properties on perpendicular directions, caused by the technology process of the production - warp and weft weaving. Glass textile used in this work is made from glass type $\mathrm{E}$ with styrene-butadiene coating layer ensuring its alkali-resistance. Glass textile reinforcement of three different square weights, produced by company Adfors, were used in this work. Their square weights were 131, 275 and $585 \mathrm{~g} / \mathrm{m}^{2}$ (Fig. 1). Each textile was applied in one and two layers respectively. 


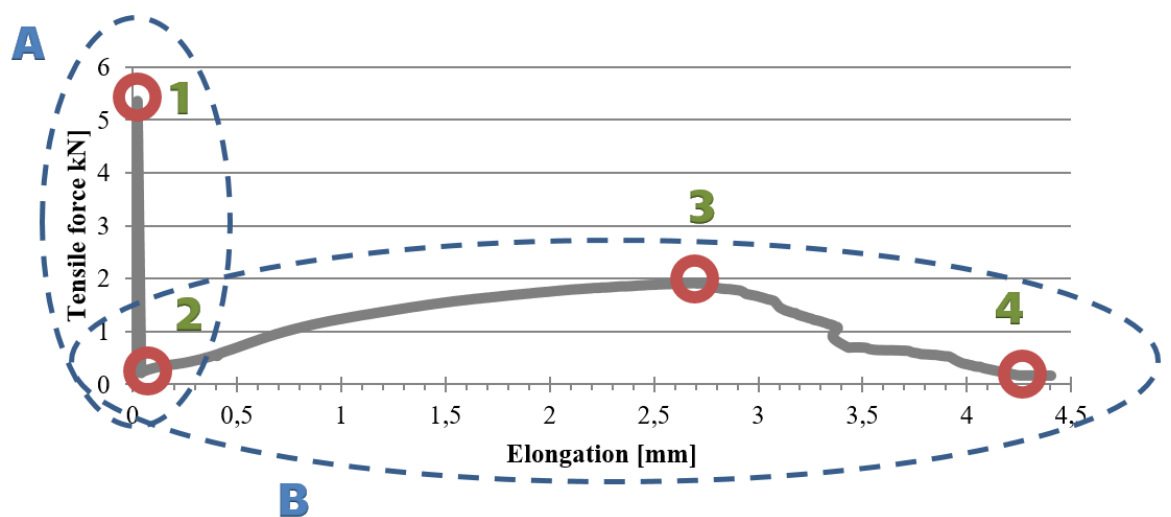

Figure 3. Typical loading chart.

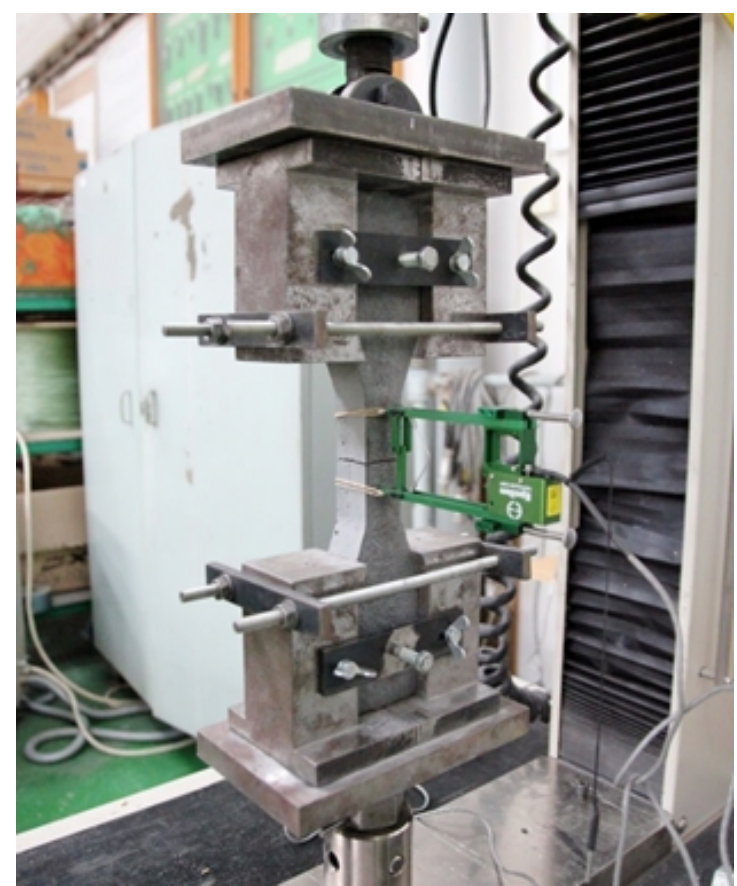

FiguRE 2. Specimen in claws with installed extensimeter.

\subsection{EXPERIMENTAL METHODS}

Determination of the flexural strength and compressive strength were carried out according to BS EN 1015-11 18]. Flexural strength measurement was executed on the accompanying prismatic specimens $40 \times 40 \times 160 \mathrm{~mm}$. The determination of the flexural strength was organized as a three-point bending test with the support span $100 \mathrm{~mm}$ and axial loading. The compressive strength was investigated by using fragments left after the bending test.

The main testing part - tensile property test - was executed on "dog-bone" specimens placed into special claws on the testing machine. The loading speed was $0.5 \mathrm{~mm} / \mathrm{min}$ and the test ended at the point of a full break-up. Several data outputs have been observed, such as time, loading strength, elongation and strain thanks to the installed extensimeter, Fig. 2
Incorporation of the reinforcement gets difficult in the interpretation of the test results, because it is necessary to take into consideration the entire failure behaviour of the specimen. That is why four main points of the test record were monitored. The characterisation of the obtained test record is illustrated in Fig. 3. Point 1 describes the strength where the first crack occurred. Point 2 is where the TRC specimen started acting again and begun to bear load again. Point 3 describes the maximal obtained strength in the textile reinforcement. Fourth point is a point when the specimen was torn apart. Area "A" is where just the cementitious matrix bears all loads; area "B" is the area where the textile reinforcement is activated.

The main aim of the experimental program was to evaluate the impact of the environment with a set of accelerated tests. This testing was inspired by Japanese code JSCE-E 549-2000 [19], which prescribes specific solutions for 60 days without an air circulation and solution renewal. Samples were submersed to $10 \% \mathrm{NaOH}$ solution, $10 \% \mathrm{H}_{2} \mathrm{SO}_{4}$ solution, reference samples were cured in water. The above described procedure includes monitoring the residual weight of samples and their visual description.

The TRC is used for a thin-walled structure elements production, which is why the freeze-thaw resistance test was included, because it could cause progress of cracks. The freeze-thaw resistance was realised according to [20]. The load cycle started with a frosting phase down to $-18^{\circ} \mathrm{C}$ lasting for four hours, and then continued with a defrosting period up to $20^{\circ} \mathrm{C}$ for another two hours (as shown on Figure 4). The defrosting is realized by flooding the climatic chamber with a water with a temperature of $20^{\circ} \mathrm{C}$. Loss of the mass is also monitored, if any occurs. The residual properties after accelerated durability tests were specifically determined on the "dog-bone" shaped specimens. All tests were carried out on three samples.

\section{Results}

The performed experimental program was focused on the assessment of the resistance of the TRC made of 


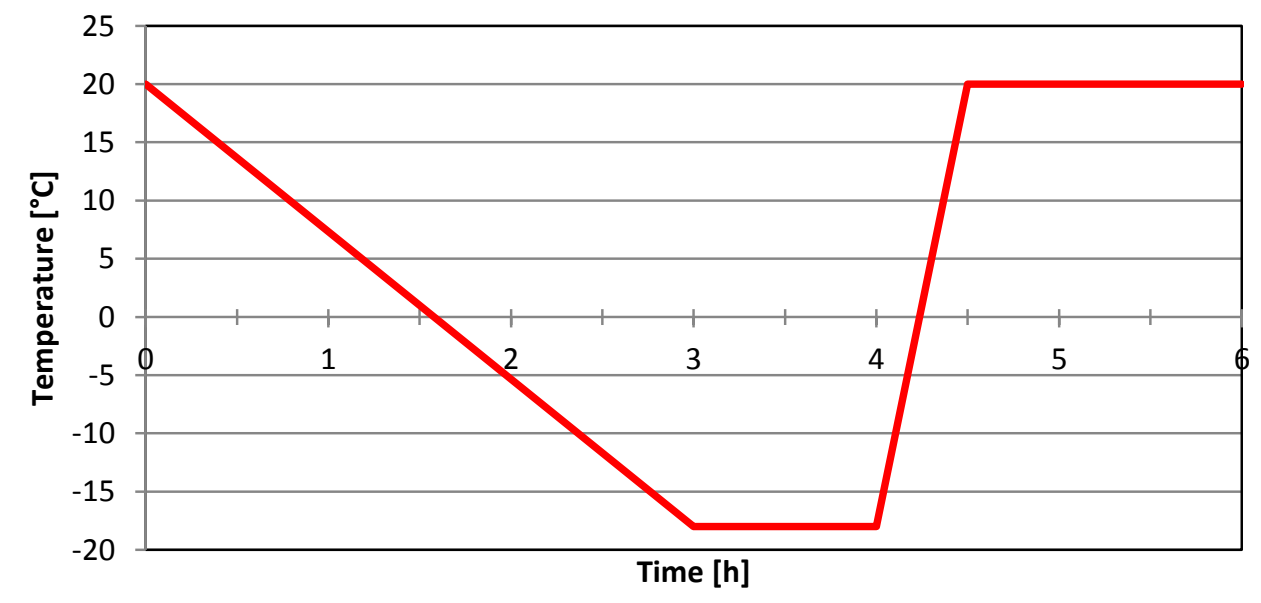

Figure 4. Freeze-thaw scheme.

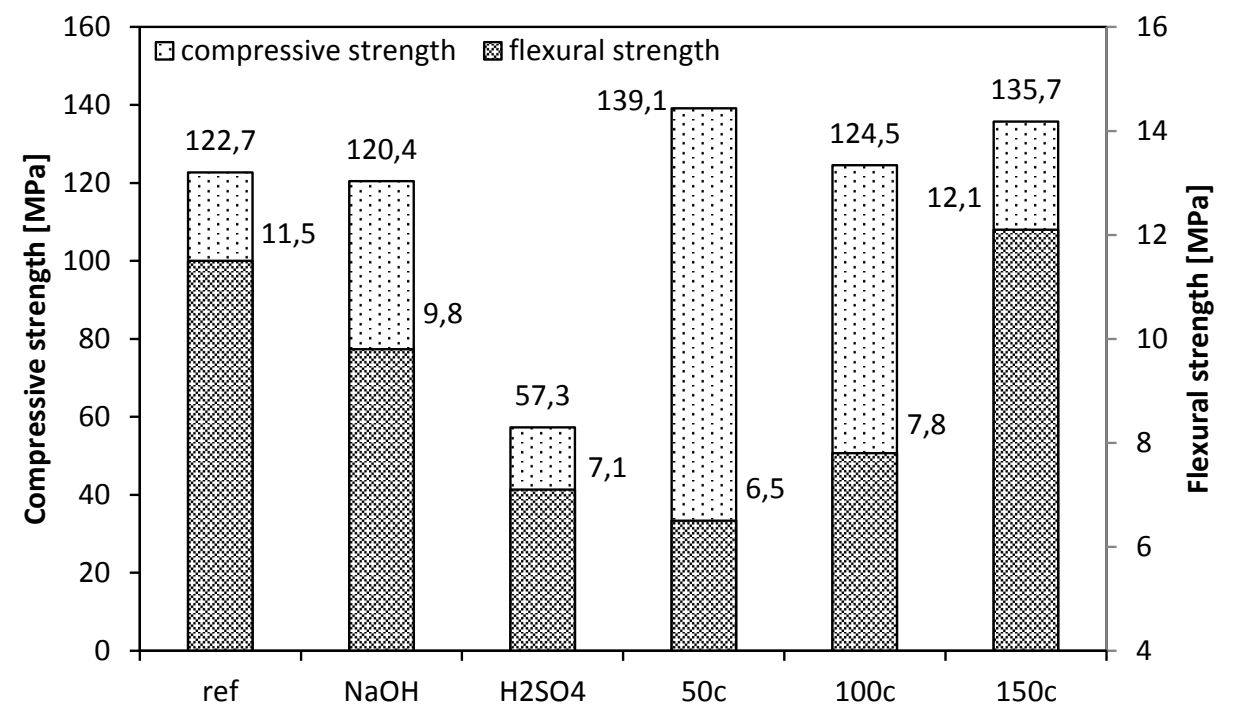

FigURE 5. Mechanical properties of used matrix.

the HPC matrix and glass textile reinforcement to various aggressive environments. The cement based matrix, which was used, was developed in a previous research, nevertheless, the determination of actual mechanical properties was necessary for the correct evaluation. Flexural and compressive strength exhibited values of $11.5 \mathrm{MPa}$ and $122.7 \mathrm{MPa}$ respectively, after 28 days, which met the initial expectations. The dominant part of the experimental program was focused on the influence of various aggressive environments, where samples were immersed to acidic and alkaline solutions for 60 days; a freeze-thaw test was in progress at the same time for different specimens. Residual values of flexural and compressive strength obtained using prismatic specimens are shown in Fig. 5

Specimens exposed to the alkaline solution exhibited a minimal loss of mass and visual changes as well; the surface was coated by a thin dark blue film, which was formed by silica fumes released from the surface. High alkaline environment leads to the metastable state of created hydrates. The alkaline solution was

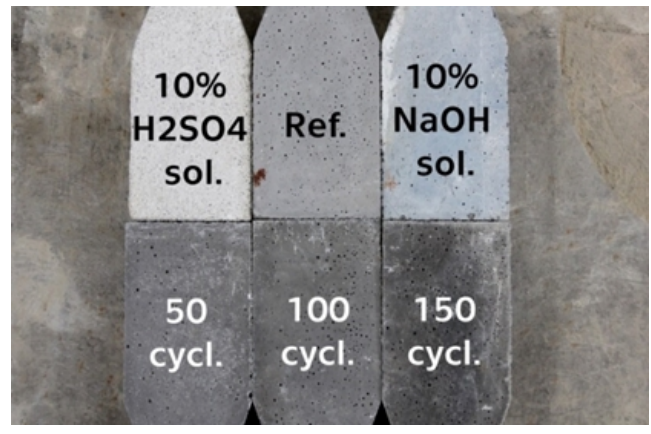

Figure 6. Studied samples after the exposure.

nearly constant during testing; $\mathrm{pH}$ dropped from 13.3 to 13.2 during 60 days of exposure. This changes well explain the minimal decay of studied mechanical properties.

However, acidic solution was significantly neutralized, which is well obvious from the $\mathrm{pH}$ changes; the initial $\mathrm{pH}$ of the acidic solution was 0.2 and increased to 3.4 after the prescribed time. This significant 


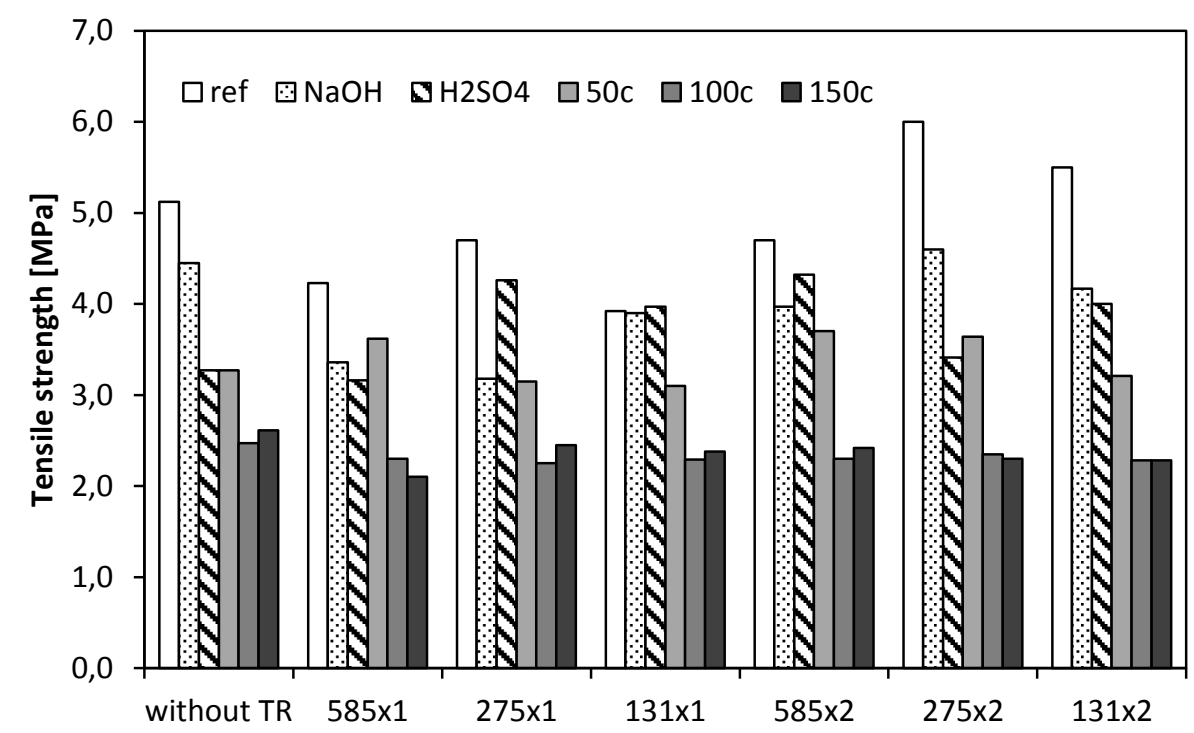

Figure 7. Tensile strength of studied TRC samples - point "1".

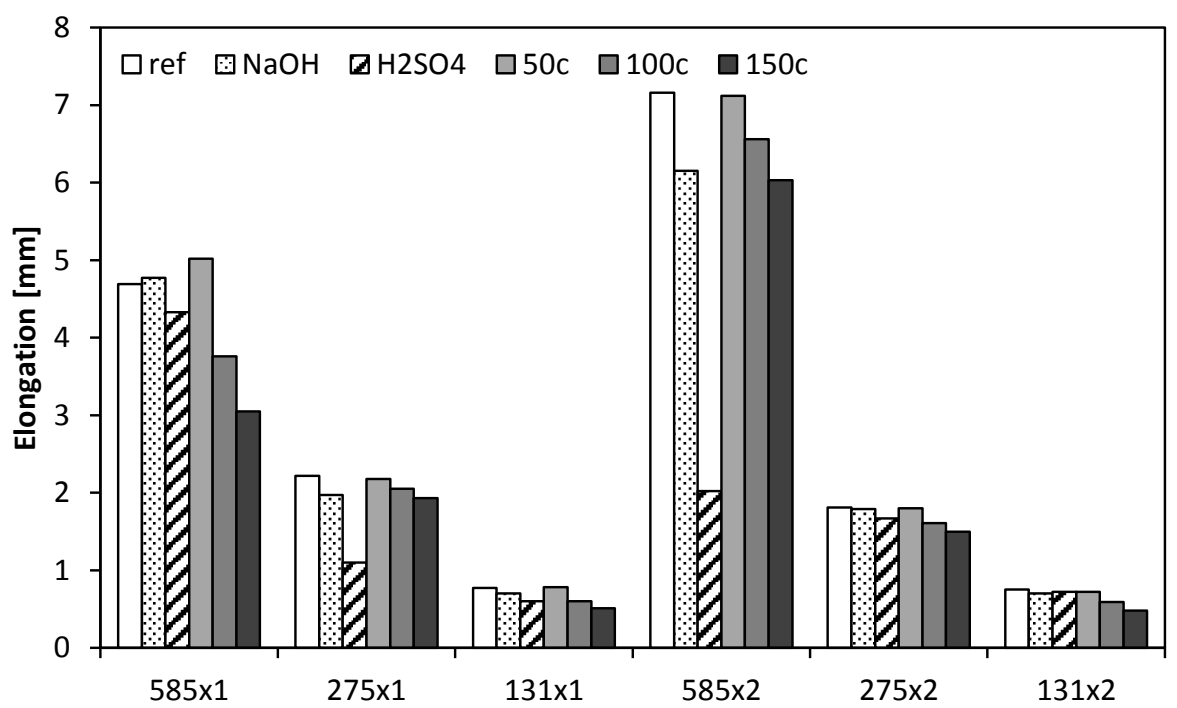

FiguRE 8. Elongation of TRC samples between the second and the fourth point.

\begin{tabular}{ccc}
\hline & $\begin{array}{c}\text { Acidic } \\
\text { environment }\end{array}$ & $\begin{array}{c}\text { Alkaline } \\
\text { environment }\end{array}$ \\
\hline Loss of mass & $9.93 \%$ & $1.57 \%$ \\
\hline
\end{tabular}

TABLE 2. Loss of mass of immersed samples.

change was accompanied by the deterioration of immersed specimens, which provided dotation of alkalinity. However, it is necessary to note that the measurement of the initial value of $\mathrm{pH}$ was on the limit of the apparatus resolution. The loss of $\mathrm{Ca}(\mathrm{OH})_{2}$ and the consequent decomposition of hydrated phases [9, 21] was accompanied by a massive loss of mass and decay of mechanical properties.

Interesting trend exhibited accompanying prismatic samples subjected to freezing-thawing. Values of flexural strength after 50 cycles decreased by more than $40 \%$, however, additional freezing-thawing led to a slight increase in comparison with the original values. It is probably caused by the additional matrix hydration. Similar conclusions could be found in work of Sahmaran et al. [22] and Chung et al. 223. The most important part of the experiment was the tensile testing of the TRC specimens. The impact of studied aggressive environments is well declared on the results of dog-bone specimens testing. The immersion of produced dog-bone samples into aggressive environment caused the expected loss of mass, however, increasing the amount of textile reinforcement did not affect this parameter. Average results are summarized in Tab. 2 for both acidic and alkaline environments. The 


\begin{tabular}{ccccccc}
\hline & \multicolumn{2}{c}{ Environment } & & \multicolumn{2}{c}{ Freeze-thaw cycles } \\
\cline { 2 - 3 } \cline { 5 - 7 } & acidic & alkaline & & $\mathbf{5 0}$ & $\mathbf{1 0 0}$ & $\mathbf{1 5 0}$ \\
\hline Without TR & 63.9 & 86.9 & & 63.9 & 48.2 & 51.0 \\
$1 \times 131$ & 74.7 & 79.4 & & 85.6 & 54.4 & 49.6 \\
$1 \times 275$ & 90.6 & 67.7 & & 67.0 & 47.9 & 52.1 \\
$1 \times 585$ & 101.3 & 99.5 & & 79.1 & 58.4 & 60.7 \\
$2 \times 131$ & 91.9 & 84.5 & & 78.7 & 48.9 & 51.5 \\
$2 \times 275$ & 56.8 & 76.7 & & 60.7 & 39.2 & 38.3 \\
$2 \times 585$ & 72.7 & 75.8 & & 58.4 & 41.5 & 41.5 \\
\hline
\end{tabular}

TABle 3. The decay of tensile strength due to action of studied environments [\%].

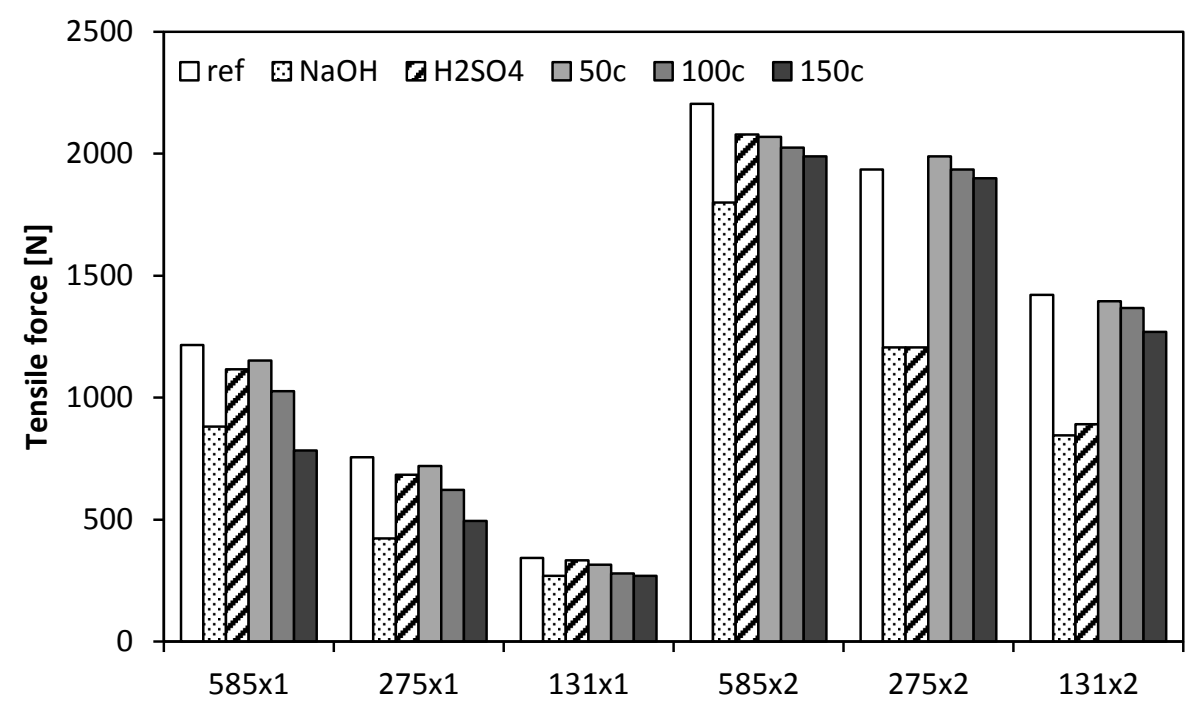

FIgURE 9. Tensile force in TRC after the first crack - point "2".

conduction of freeze-thaw cycling did not cause any mass loss. The documentation of visual condition of studied samples is shown in Fig. 6. The decay of the determined tensile strength is introduced in Tab. 3 . The absolute values of the obtained tensile strength after the freezing-thawing are introduced in Fig. 7 these values present the stress corresponding to the crack initiation - point 1 according to Fig. 3 .

The elongation between points two and four is a crucial parameter describing the failure mode of the samples, because the brittle rupture is not desirable for thin-walled structures. This parameter was affected by the reduced cohesion of the TR and used matrix, which is well visible in Fig. 8 . Results obtained on the samples subjected to the cycle freezing-thawing are nearly similar with the reference samples.

Figure 9 describes the behaviour of a specimen after the first crack occurs. Values of force corresponding to point " 2 " are significantly affected by the action of the aggressive environment, it is well visible on the influence of freezing-thawing. Reason for this result is the fact that freezing-thawing affects the whole mass in comparison with the surface degradation induced by solutions. We can clearly see the difference between one and two layers of all reinforcement, which is more than double in some cases. The biggest posi- tive effect appeared in the case of reinforcements with a lower square weight. The degree of reinforcement has demonstrable effect on the after-crack behaviour.

Figure 10 shows the maximum force achieved in the textile reinforcement after the first crack - point " 3 ". This moment was followed by a slow decrease, which is positive because of the absence of a fast rupture, which is undesirable. The biggest negative effect was caused by $\mathrm{NaOH}$ solution, where the most noticeable strength decrease was almost $31 \%$ in the case of two layers of R 585 A101 reinforcement compared to the reference samples. It is a very surprising result because of the presence of an alkali resistant coating on the reinforcement.

\section{Conclusion}

This research programme describes the behaviour of the TRC after an exposure to various aggressive environments. Test specimens were dog-bone shaped, made of the HPC cement based matrix with one or two layers of glass textile reinforcement. Besides being subjected to freezing-thawing, the TRC samples were also submersed to chemically aggressive solutions - alkaline and acidic. The applied accelerated test simulated the impact of an external environment. 


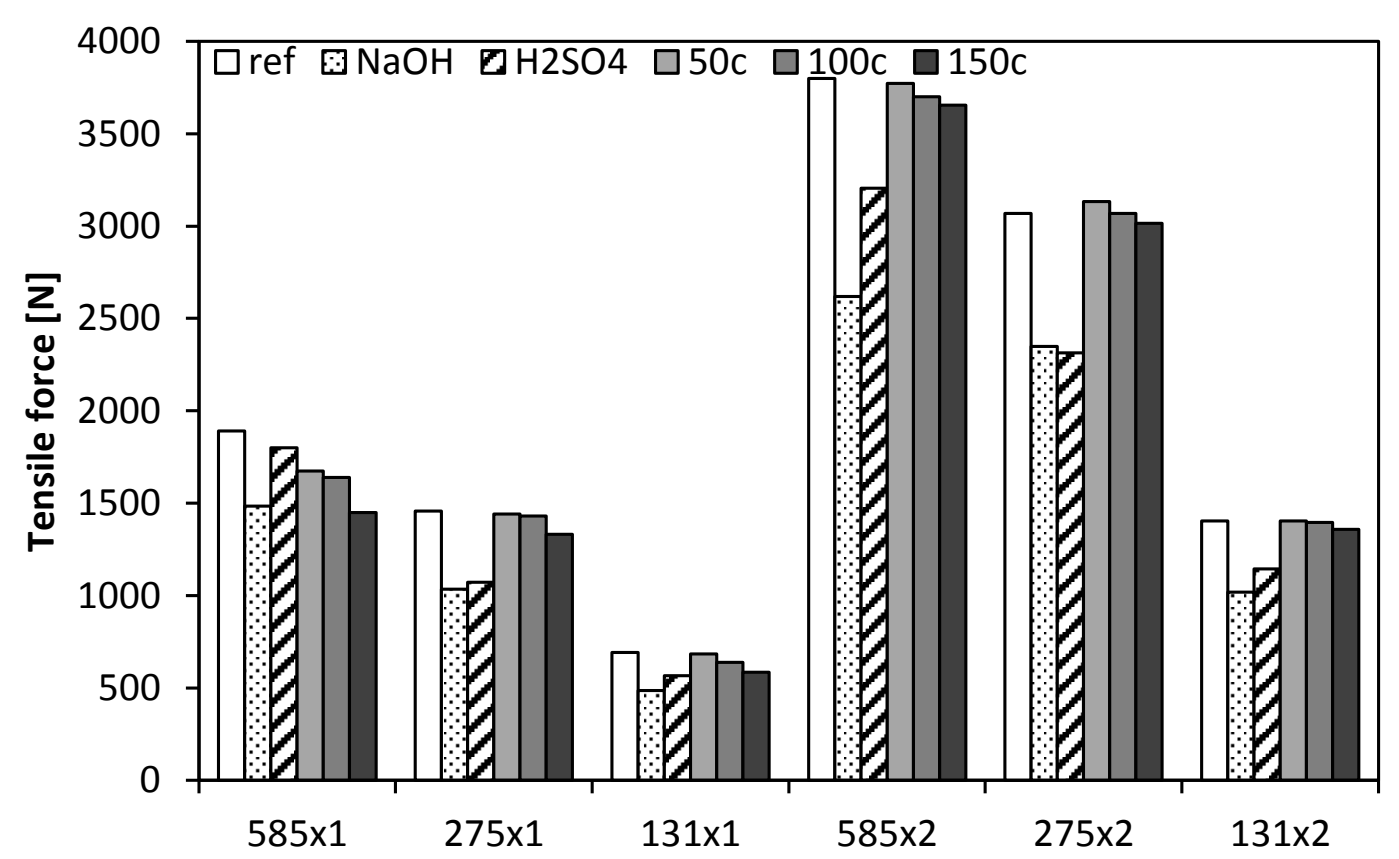

Figure 10. Maximal tensile force in TRC after the first crack - point " 3 ".

Freeze-thaw cycles seem to be a crucial parameter for the TRC. Number of studies declared sufficient resistance of the HPC to this type of exposure, however, a limited cross-section of the TRC amplifies the negative impact of the micro-crack propagation. A very interesting finding is the stimulated self-healing of the HPC matrix induced by freezing. The observed effect is probably caused by the surplus of the active mineral additive. The negative frost effect is determined by the character of the consequent deterioration - presence of cracks. However, the action of acidic and alkaline environments, respectively, breaks the material from the surface, which was well visible on the resulting mass loss. The alkaline environment had a significant impact on the durability of the used glass reinforcement, despite of the application of the alkali-resistant coating. The acidic environment led to the weakening of the matrix and mutual cohesion with the used TR. That is why we can conclude that the crucial parameter is the frost resistance from the point of view of ways of the environment loading. Very important fact in the composite behaviour is the type and amount of reinforcement layers. The lightest textile reinforcement $\left(131 \mathrm{~g} / \mathrm{m}^{2}\right)$ showed to be inappropriate for reinforcing. The strongest textile $\left(585 \mathrm{~g} / \mathrm{m}^{2}\right)$ seems to be adequate. Generally, specimens with two layers exhibited approximately two times better properties compared to just one layer. However, the final durability and resistance to the actions of an aggressive environment will be crucial parameters for the design of the TRC structures.

\section{ACKNOWLEDGEMENTS}

This research was supported by project LTC18063.

\section{REFERENCES}

[1] Du, Y. et al.: Experimental study on basalt textile reinforced concrete under uniaxial tensile loading. Construction and Building Materials, 138, 2017, p. 88-100. DOI:10.1016/j.conbuildmat.2017.01.083

[2] Zargaran, M. et al.: Minimum reinforcement ratio in TRC panels for deflection hardening flexural performance. Construction and Building Materials, 137, 2017, p. 459-469. DOI:10.1016/j.conbuildmat.2017.01.091

[3] Sharei, E. et al.: Structural behavior of a lightweight, textile-reinforced concrete barrel vault shell. Composite Structures, 171, 2017, p. 505-514. DOI:10.1016/j.compstruct.2017.03.069

[4] Chira, A. et al.: Property improvements of alkali resistant glass fibres/epoxy composite with nanosilica for textile reinforced concrete applications. Materials \& Design, 89, 2016, p. 146-155. DOI:10.1016/j.matdes.2015.09.122

[5] Williams Portal, N. et al.: Tensile behaviour of textile reinforcement under accelerated ageing conditions. Journal of Building Engineering, 5, 2016, p. 57-66. DOI:10.1016/j.jobe.2015.11.006

[6] Kong, K. et al.: Comparative characterization of the durability behaviour of textile-reinforced concrete (TRC) under tension and bending. Composite Structures, 179, 2017, p. 107-123. DOI:10.1016/j.compstruct.2017.07.030

[7] Butler, M. et al.: Experimental investigations on the durability of fibre-matrix interfaces in textile-reinforced concrete. Cement and Concrete Composites, 31 (4), 2009, p. 221-231. DOI:10.1016/j.cemconcomp.2009.02.005

[8] Butler, M. et al.: Durability of textile reinforced concrete made with AR glass fibre: effect of the matrix composition. Materials and Structures, 43 (10), 2010, p. 1351-1368. DOI:10.1617/s11527-010-9586-8 
[9] Reiterman, P., Tomek, J.: Resistance of Concrete with Metakaolin Addition to Acid Environment. Key

Engineering Materials, 677, 2016, p. 144-149. DOI:10.4028/www.scientific.net/KEM.677.144

[10] Wang, Z. et al.: Deterioration of fracture toughness of concrete under acid rain environment. Engineering Failure Analysis, 77, 2017, p. 76-84. DOI:10.1016/j.engfailanal.2017.02.013

[11] Basheer, P.A.M. et al.: Predictive models for deterioration of concrete structures. Construction and Building Materials, 10 (1), 1996, p. 27-37. DOI:10.1016/0950-0618(95)00092-5

[12] Nobili, A.: Durability assessment of impregnated Glass Fabric Reinforced Cementitious Matrix (GFRCM) composites in the alkaline and saline environments. Construction and Building Materials, 105, 2016, p. 465-471. DOI:10.1016/j.conbuildmat.2015.12.173

[13] Orlowsky, J., Raupach, M.: Durability model for AR-glass fibres in textile reinforced concrete. Materials and Structures, 41 (7), 2007, p. 1225-1233. DOI:10.1617/s11527-007-9321-2

[14] Orlowsky, J., Raupach, M.: Modelling the loss in strength of AR-glass fibres in textile-reinforced concrete. Materials and Structures, 39 (6), 2006, p. 635-643. DOI:10.1617/s11527-006-9100-5

[15] Holčapek, O. et al.: ANALYSIS OF MECHANICAL PROPERTIES OF HYDROTHERMALLY CURED HIGH STRENGTH CEMENT MATRIX FOR TEXTILE REINFORCED CONCRETE. Acta Polytechnica, 55 (5), 2015, p. 313. DOI:10.14311/AP.2015.55.0313
[16] Holčapek, O. et al.: Using of Textile Reinforced Concrete Wrapping for Strengthening of Masonry Columns with Modified Cross-section Shape. Procedia Engineering, 195, 2017, p. 62-66. DOI:10.1016/j.proeng.2017.04.524

[17] BS EN 12390-3 - Testing hardened concrete - Part 3: Compressive strength of test specimens, BSI 2009.

[18] BS EN 1015-11 - Methods of test for mortars for masonry - Part 11: Determination of flexural and compressive strength of hardened mortars, BSI 1999.

[19] JSCE-E 549-2000 - TEST METHOD FOR WATER, ACID AND ALKALI RESISTANCE OF CONTINUOUS FIBER SHEETS, JSCE 2000. http://www.jsce.or.jp/ committee/concrete/e/newsletter/newsletter01/ recommendation/FRP-sheet/2-10.pdf [2018-08-01].

[20] CSN 731322 - Determination of frost resistance of concrete, CSI 1968.

[21] A.M. Neville, Properties of concrete. 4th and final ed. Harlow: Longman Group, 1995. ISBN 978-0-582-23070-5.

[22] Sahmaran, M. et al.: Self-healing capability of cementitious composites incorporating different supplementary cementitious materials. Cement and Concrete Composites, 35 (1), 2013, p. 89-101. DOI:10.1016/j.cemconcomp.2012.08.013

[23] Chung, C.-W. et al.: Chloride ion diffusivity of fly ash and silica fume concretes exposed to freeze-thaw cycles. Construction and Building Materials, 24 (9), 2010, p. 1739-1745. DOI:10.1016/j.conbuildmat.2010.02.015 